\title{
Hemicrania Continua With Scintillating Scotoma: A Rare Presentation
}

\author{
Adil Hussein ${ }^{1}$, Tham Han Shu ${ }^{1}$, Mei Fong Chong ${ }^{2}$, Chun Fai Cheah ${ }^{3}$ \\ 1. Ophthalmology, School of Medical Sciences, Universiti Sains Malaysia, Kubang Kerian, MYS 2. Ophthalmology, \\ Hospital Raja Permaisuri Bainun, Ipoh, MYS 3. Neurology, Hospital Raja Permaisuri Bainun, Ipoh, MYS
}

Corresponding author: Adil Hussein, adilh@usm.my

\begin{abstract}
Headache can be a primary or secondary disorder. The characteristics of headache and its associated features, especially the presence of red flag signs, are important in distinguishing secondary from primary causes. Hemicrania continua is a type of primary headache disorder characterized by a continuous unilateral headache with episodes of exacerbations and association with cranial autonomic symptoms, which include several ocular symptoms. The absolute response to indomethacin remains the hallmark of this disease. We would like to report a rare case of hemicrania continua with scintillating scotoma during exacerbations apart
\end{abstract} from the typical autonomic features of conjunctival injection, ptosis, eyelid edema, and lacrimation.

Categories: Neurology, Ophthalmology

Keywords: hemicrania continua, trigeminal autonomic cephalalgia, headache with aura, scintillating scotoma

\section{Introduction}

Hemicrania continua $(\mathrm{HC})$ is a rare primary headache disorder. It is grouped under trigeminal autonomic cephalalgia after the revision of diagnostic criteria in the International Classification of Headache Disorders, 3rd edition (ICHD-3) Beta in 2013 [1], which include the characteristics of persistent unilateral chronic headache of more than three months, with episodes of exacerbations that respond absolutely to indomethacin. The autonomic features associated include eyelid edema, conjunctival injection with lacrimation, miosis and/or ptosis, rhinorrhoea, and facial flushing. The diagnostic criteria had been revised in 2013 based on the study reported cases with wider autonomic features and a side-shifting headache [2]. Migrainous features had been presented as part of hemicrania continua, however, visual aura was not commonly reported. By far, there have been only single reports or case series of hemicrania continua with visual symptoms mainly described as flashes or black spots during pain exacerbations [2-3]. Hence, we report a rare case of $\mathrm{HC}$ associated with documented scintillating scotoma as visual aura apart from the presence of typical autonomic features.

Review began 09/17/2020 Review ended 09/22/2020 Published 09/27/2020

\section{() Copyright 2020}

Hussein et al. This is an open access article distributed under the terms of the Creative Commons Attribution License CC-BY 4.0., which permits unrestricted use, distribution, and reproduction in any medium, provided the original author and source are credited.

\section{Case Presentation}

A 22-year-old Indian lady presented with acute exacerbation of left-sided headache over the frontoparietal region and left eye pain for one day. The pain was throbbing in nature. It was associated with mild drooping and swelling of the left upper eyelid, eye redness, tearing, photophobia, and reduced periphery vision over the left eye. The headache was partially relieved by vomiting; otherwise, there was no body weakness and no history of trauma. She denied any blurring of vision and diplopia. Further history revealed that she had been having persistent headaches with similar recurrent episodes of exacerbations of left-sided headache and left eye pain for the past one year with similar associated ocular symptoms and nasal congestion. The visual disturbances of reduced periphery vision and photophobia occurred during headache exacerbations. It began at the paracentral region, gradually enlarged towards the periphery. The visual symptoms lasted for about 24 hours together with the headache spikes and resolved when the headache was partially relieved by bouts of vomiting. There was no associated phonophobia and no identifiable aggravating factor for the headache. She denied a history of overuse of analgesics. She had no personal and family history of migraine.

Upon initial presentation, visual acuity over both eyes was 6/9. Her left upper eyelid was mildly edematous with mild ptosis of $2 \mathrm{~mm}$. Conjunctiva was injected. Otherwise, there was no anisocoria or relative afferent pupillary defect. The bilateral fundus was normal with no disc swelling, and extraocular movement was normal. The confrontation visual field test revealed a concentric contraction field defect over the left eye. Otherwise, the neurological examination was unremarkable. Secondary etiologies were excluded whereby her magnetic resonance imaging, magnetic resonance venography, and angiography brain were normal. She was referred to the neurology team and was diagnosed with hemicrania continua based on the criteria of the International Classification of Headache Disorders and resolution of headache with indomethacin.

Humphrey's visual field test was done one month later during the follow-up visit where she developed a side-shifting headache affecting the right frontal and temporal region with features similar to the left side. The test revealed nasal hemianopia over the right eye and normal visual field over the left eye (Figure 1). A subsequent visual field test that was done 10 months later, while the patient was having a left-sided 


\section{Cureus}

Left Eye

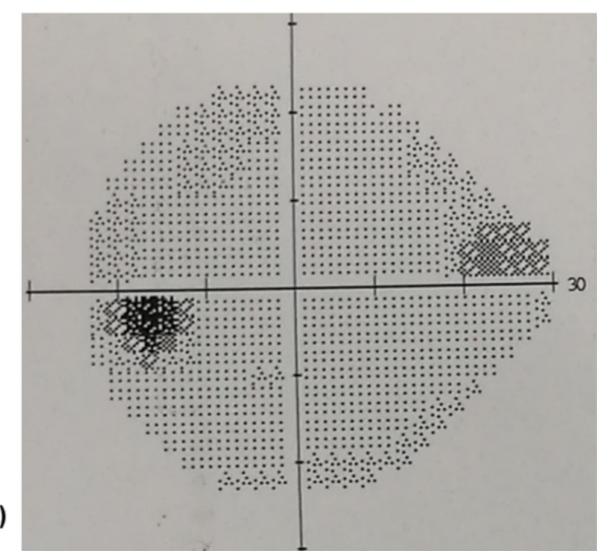

A)

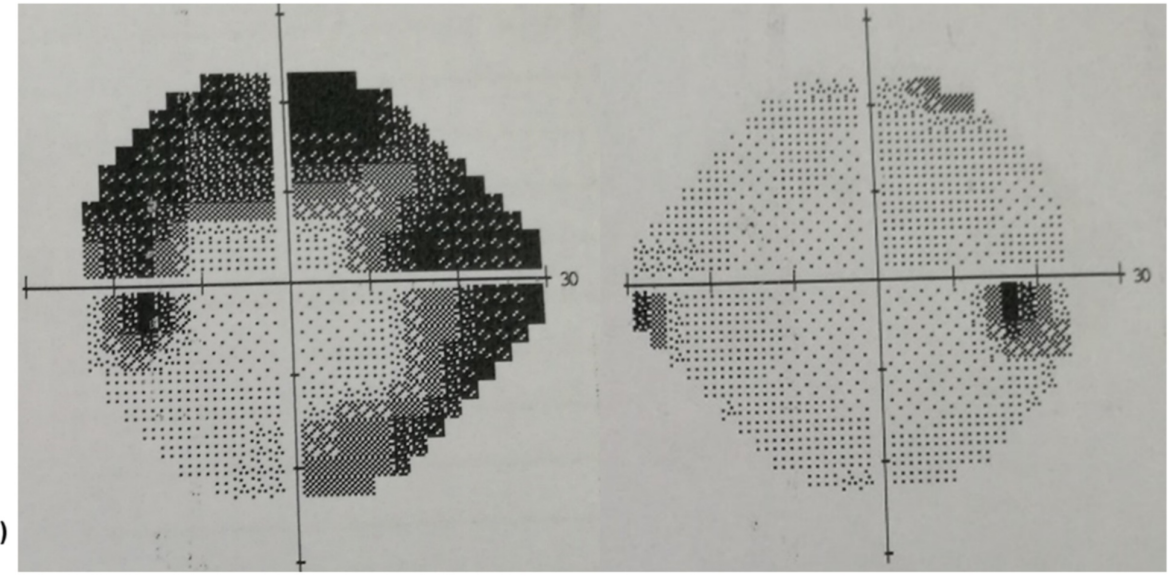

FIGURE 1: Sequential Humphrey 24-2 automated perimetric visual fields

Performed at:

A) One month during follow-up with right-sided headache exacerbation. There was a right nasal hemianopia. The left visual field was normal.

B) 10 months. There was complete resolution of the right field defect and the presence of left ring scotoma during left-sided headache exacerbation.

The patient was treated with indomethacin $50 \mathrm{mg}$ bid initially and was gradually increased to $75 \mathrm{mg}$ bid with a resolution of her headache, visual aura, and autonomic symptoms. Indomethacin could be tapered to 50 $\mathrm{mg}$ daily over the course of two months. Attempts to discontinue the medication resulted in a recurrence of pain and aura. She developed the side-effects of gastritis later and could not tolerate indomethacin. Her medications were changed to verapamil $40 \mathrm{mg}$ tid, flunarizine $5 \mathrm{mg}$ at night, and Sumatriptan $50 \mathrm{mg}$ as needed. She had been followed up for the past 12 months. The intensity of the background headache was much improved (reduced from $4 / 10$ to $2 / 10$ on the subjective analog scale), with occasional weekly episodes of exacerbations as compared to the thrice-weekly exacerbations prior to treatment. The headache exacerbations predominantly affected the left side. Her visual aura remained the same during episodes of exacerbations.

\section{Discussion}

Hemicrania continua (HC) is currently grouped under trigeminal autonomic cephalalgias (TACs) according to the International Classification of Headache Disorders (ICHD), based on the presence of prominent cranial autonomic features with worsening of headache, which seemed comparable to cluster headaches and paroxysmal hemicrania $[1,4]$. Based on the presence of the clinical phenotype of cranial autonomic symptoms and unilaterality, it was suggested that HC might share a pathophysiological similarity with TACs $[5]$. 
The mechanism for TACs is the role of trigeminal-autonomic reflex, which is a reflex pathway consisting of a brainstem connection between the trigeminal nerve and facial cranial nerve parasympathetic outflow [4,67]. A functional neuroimaging study of $\mathrm{HC}$ revealed the activation of the contralateral posterior hypothalamus and ipsilateral dorsal rostral pons in association with the headache [8]. A positive response to indomethacin is the typical feature of headache and diagnostic criteria peculiar to HC $[1,4]$, as compared to other TACs.

Clinically, HC is characterized by a strictly persistent unilateral headache of moderate-intensity without a pain-free interval of more than three months, with episodes of exacerbations of severe intensity, which were associated with the presence of cranial autonomic features [2]. Apart from the presence of typical cranial autonomic features, which include conjunctival injection, lacrimation, nasal congestion, eyelid edema, and ptosis, as described by a clinical study done by Cittadini et al. [2], the most peculiar clinical finding in our patient was the complaint of visual aura in the form of transient scintillating visual scotoma that occurred during episodes of headache exacerbation, which was rare. To date, HC with associated visual aura has not been commonly reported. Peres et al. reported a case series of four patients with visual aura in the form of white flashes, sparkles, and black spots. The aura occurred preceding or during exacerbation of the headache, involving either the ipsilateral, contralateral, or both eyes [3]. From this case series, the author suggested that the aura might be pathophysiologically related to HC given the negative history of migraine in the patient and the family, as well as the response of both headache and aura to indomethacin. Recently, Auffenberg et al. described the first case of HC with classic scintillating scotoma lasting about 30 minutes during the headache exacerbation [9]. To our knowledge, our patient is the first reported case of $\mathrm{HC}$ with documented transient visual disturbance of scintillating scotoma ipsilateral to the side of headache exacerbation. Similar to the above case series reported, indomethacin gave complete relief of the headache, cranial autonomic features, and visual symptoms. In our patient, the visual aura and headache exacerbations were side-shifting, though affecting the left side most of the time.

Migrainous features were present in our patient but the diagnosis of migraine was less likely in view of the negative family history and the characteristic of unilateral headache associated with the presence of cranial autonomic features, which was more suggestive of a variant of TACs. The persistent nature of headache without a pain-free interval and dramatic response to indomethacin further favors the diagnosis of $\mathrm{HC}$ in this case. The visual symptoms described fulfilled the criteria of migraine with aura in ICHD. There were no visual symptoms observed independently of the headache. However, the resolution of both aura and headache with indomethacin suggests that there may be a pathophysiological correlation between aura and HC.

Table 1 lists the clinical features of trigeminal cephalalgias. 


\begin{tabular}{|c|c|c|c|c|}
\hline & Cluster headache & $\begin{array}{l}\text { Paroxysmal } \\
\text { hemicrania }\end{array}$ & $\begin{array}{l}\text { Short-lasting } \\
\text { unilateral } \\
\text { neuralgiform } \\
\text { headache attacks }\end{array}$ & Hemicrania continua \\
\hline Sex (F:M) & $1: 3$ & 1:1 1 & 1: 1.5 & 2: 1 \\
\hline Site of pain & $\begin{array}{l}\text { Orbital, } \\
\text { supraorbital, } \\
\text { temporal }\end{array}$ & $\begin{array}{l}\text { Orbital, } \\
\text { supraorbital, } \\
\text { temporal }\end{array}$ & $\begin{array}{l}\text { Orbital, supraorbital, } \\
\text { temporal, and/or } \\
\text { other trigeminal } \\
\text { distribution }\end{array}$ & Temporal, orbital, retro-orbital, frontal \\
\hline Type of pain & Stabbing/throbbing & Stabbing/throbbing & Stabbing/throbbing & $\begin{array}{l}\text { Baseline - dull pain. Exacerbations - } \\
\text { throbbing, sharp during }\end{array}$ \\
\hline Severity & Excruciating & Severe & Severe & $\begin{array}{l}\text { Baseline - mild to moderate. } \\
\text { Exacerbations - moderate to severe }\end{array}$ \\
\hline Attack frequency & $\begin{array}{l}1 \text { every other day - } \\
8 / \text { day }\end{array}$ & $>5 /$ day & $\geq 1 /$ day & $\begin{array}{l}\text { Continuous with exacerbations of } \\
\text { moderate or greater intensity, or } \\
\text { intermittent with remission period of } \geq \\
24 \text { hours }\end{array}$ \\
\hline Duration of attack & $15-180$ minutes & $2-30$ minutes & $1-600$ seconds & 30 minutes to 3 days \\
\hline Autonomic features & Yes & Yes & Yes & Yes \\
\hline $\begin{array}{l}\text { Migrainous features eg } \\
\text { nausea, photophobia, } \\
\text { phonophobia }\end{array}$ & ++ & ++ & + & +++ \\
\hline Indomethacin effect & No & Yes & No & Yes \\
\hline Treatment & $\begin{array}{l}\text { Oxygen, } \\
\text { Sumatriptan }\end{array}$ & $\begin{array}{l}\text { Indomethacin, } \\
\text { Sumatriptan } \\
\text { (partial relief) }\end{array}$ & $\begin{array}{l}\text { No effective } \\
\text { treatment }\end{array}$ & $\begin{array}{l}\text { Indomethacin, Sumatriptan (partial } \\
\text { relief) }\end{array}$ \\
\hline
\end{tabular}

TABLE 1: Overview of clinical features of trigeminal cephalalgias

\section{Conclusions}

Strictly unilateral headache is a red flag. A detailed history and appropriate investigations are mandatory to exclude secondary causes. The diagnosis of $\mathrm{HC}$ is mainly clinical and remains a diagnosis of exclusion. It is a rare primary headache, which can present with side-shifting exacerbations, autonomic ocular features, and, rarely, a scintillating visual field defect as visual aura during episodes of exacerbation. Aura symptoms are not necessarily a specific feature of migraines. There may be a potential link with visual aura, which is currently not a diagnostic criterion of $\mathrm{HC}$ and needs to be further studied.

\section{Additional Information}

\section{Disclosures}

Human subjects: Consent was obtained by all participants in this study. Conflicts of interest: In compliance with the ICMJE uniform disclosure form, all authors declare the following: Payment/services info: All authors have declared that no financial support was received from any organization for the submitted work. Financial relationships: All authors have declared that they have no financial relationships at present or within the previous three years with any organizations that might have an interest in the submitted work. Other relationships: All authors have declared that there are no other relationships or activities that could appear to have influenced the submitted work.

\section{References}

1. International Headache Society: Headache Classification Committee of the International Headache Society (IHS). The International Classification of Headache Disorders, 3rd edition. Cephalalgia. 2018, 38:1-211. 10.1177/0333102417738202

2. Cittadini E, Goadsby PJ: Hemicrania continua: a clinical study of 39 patients with diagnostic implications . Brain. 2010, 133:1973-1986. 10.1093/brain/awq137

3. Peres M, Slow HC, Rozen TD: Hemicrania continua with aura . Cephalalgia. 2002, 22:246-248. 


\section{Cureus}

10.1046/j.1468-2982.2002.00325.x

4. Goadsby PJ, Lipton RB: A review of paroxysmal hemicranias, SUNCT syndrome and other short-lasting headaches with autonomic feature, including new cases. Brain. 1997, 120:193-209. 10.1093/brain/120.1.193

5. Goadsby PJ, Cittadini E, Burns B, Cohen AS: Trigeminal autonomic cephalalgias: diagnostic and therapeutic developments. Curr Opin Neurol. 2008, 21:323-330. 10.1097/WCO.0b013e3282fa6d76

6. May A, Goadsby PJ: The trigeminovascular system in humans: pathophysiologic implications for primary headache syndromes of the neural influences on the cerebral circulation. J Cereb Blood Flow Metab. 1999, 19:115-127. 10.1097/00004647-199902000-00001

7. Akerman S, Holland PR, Summ O, Lasalandra MP, Goadsby PJ: A translational in vivo model of trigeminal autonomic cephalalgias: therapeutic characterization. Brain. 2012, 135:3664-3675. 10.1093/brain/aws249

8. Matharu MS, Cohen AS, McGonigle DJ, Ward N, Frackowiak RS, Goadsby PJ: Posterior hypothalamic and brainstem activation in hemicrania continua. Headache. 2004, 44:747-761. 10.1111/j.15264610.2004.04141.x

9. Auffenberg E, Bender F, Freilinger T: Hemicrania continua associated with classic scintillating scotoma . Case Rep Neurol. 2018, 10:83-87. 10.1159/000487881 